\title{
Alkali Activation of Silicate Mine-Tailings: Response to Different Activator Sources ${ }^{\dagger}$
}

\author{
Priyadharshini Perumal * and Mirja Illikainen * \\ Fiber and Particle Engineering Research Unit, University of Oulu, 90014 Oulu, Finland \\ * Correspondence: priyadharshini.perumal@oulu.fi (P.P.); Mirja.Illikainen@oulu.fi (M.I.) \\ + Presented at the 1st International Conference on Smart Materials for Sustainable Construction-SMASCO \\ 2019, Luleå, Sweden, 10-12 December 2019.
}

Published: 18 November 2019

\begin{abstract}
To attain sustainability in construction industries, it is important to explore industrial sidestreams as a potential replacement for traditional construction materials. This will avoid the depletion of natural resources and helps in preserving the environment. In this way, mining industry attracts the attention of scientific community for the huge volume of tailings generated along with the problem of disposal. This paper mainly focuses on silicate tailings (MT) from two different mining sources with high magnesium (HM) and high alumina (HA) content. To study the possibility of using these tailings as precursors in alkali activation, different activators such as, sodium silicate $\left(\mathrm{Na}_{2} \mathrm{SiO}_{3}\right)$, sodium sulphate $\left(\mathrm{Na}_{2} \mathrm{SO}_{4}\right)$ and sodium carbonate $\left(\mathrm{Na}_{2} \mathrm{CO}_{3}\right)$ were employed. It was noted that the mine tailings took longer time to set in case of activators other than sodium silicate. The milled tailings were co-grinded with the respective solid activators $(10 \%)$ and mixed with $30 \%$ of sodium silicate solution (accelerates setting), to make cylindrical paste specimens. The specimens were cured at $60{ }^{\circ} \mathrm{C}$ for $24 \mathrm{~h}$. The results shown that tailings rich in magnesium (MT-HM) activated with sodium carbonate gives high early age strength i.e., 60\% increase in average strength compared to other activators. Whereas, sodium silicate helped in achieving $10 \%$ increase in early age strength of high alumina tailings (MT-HA). However, this was not the case for the later ages. At 7th day of testing, sodium silicate activated MT-HM shown a strength improvement from $2 \mathrm{MPa}$ to $6 \mathrm{MPa}$ with the formation of magnesium silicate hydrate and hydrotalcite. MT-HA activated with sodium sulphate resulted in a maximum strength of $8.5 \mathrm{MPa}$ due to the ettringite and zeolite in the system. Sodium carbonate does not show comparable results at 7th day of testing though it shown improvement in strength with age. It is also important to consider that there are other oxides like calcium and iron present in these tailings which could also have impacted the results.
\end{abstract}

Keywords: mine tailings; silicate tailings; alkali activation; compressive strength

Acknowledgments: The authors gratefully acknowledge the financial support received from the project "Geomins-Steps towards the use of mine tailings in geopolymer materials," funded by Academy of Finland (24302993).

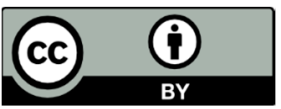

(C) 2019 by the authors. Licensee MDPI, Basel, Switzerland. This article is an open access article distributed under the terms and conditions of the Creative Commons Attribution (CC BY) license (http://creativecommons.org/licenses/by/4.0/). 